\title{
O PAPEL DEMOCRÁTICO DA SOCIEDADE CIVIL EM QUESTÃO
}

Rousiley C. M. Maia

As duas últimas décadas foram marcadas por renovado interesse pelo chamado "retorno da sociedade civil" ou "redescoberta da sociedade civil". Diversos autores encontram na sociedade civil possibilidades de revitalizar impulsos políticos dos cidadãos e revigorar o poder de comunidades ${ }^{1}$; treinar eficazmente cidadãos; construir hábitos de respeito e cooperação ${ }^{2}$; combater o individualismo e proporcionar alternativas para a política do autointeresse ${ }^{3}$; representar vozes de grupos marginalizados e excluídos da esfera políti$\mathrm{ca}^{4}$; e limitar a intromissão de burocracias na condução da vida cotidiana e revitalizar a esfera pública ${ }^{5}$.

Há diversas e boas razões a sustentar esse entusiasmo e essa renovada preocupação em investigá-la. Nos anos 1980 e 1990, a derrocada de modelos político-econômicos

\footnotetext{
${ }^{1}$ Ver Keane (1998), Bell (2000), Bellah (2000), Eberly (2000), Walzer (2002).

${ }^{2}$ Ver Putnam (1995, 1996, 2000).

${ }^{3}$ Ver Touraine (1988), Alexander (2006), Cohen e Arato (1992a, 1992b), Habermas (1997), Gurza Lavalle, Acharya e Houtzager (2005).

${ }^{4}$ Ver Young (2002), Melucci (1996), Doimo (1995), Dagnino (2002), Baiocchi (2006), Scherer-Warren (1999, 2006).

${ }^{5}$ Ver Habermas (1997), Bohman (2000), Warren (2001), Avritzer (2002).
} 
baseados em forte intervencionismo estatal, como o socialismo, ou o descontentamento com modelos sustentados em uma confiança excessiva no mercado, em países de capitalismo avançado e de tradição liberal-democrática, levaram a um crescente ceticismo quanto à possibilidade de o Estado e o mercado responderem adequadamente às necessidades dos cidadãos e proverem eficazmente oportunidades e bens públicos. Além disso, a emergência da democracia em diversos locais no leste europeu e na antiga União Soviética e a consolidação da democracia na América Latina e em diversas partes do mundo em desenvolvimento ajudaram a estabelecer o status de movimentos sociais e da ação coletiva como veículos fortes o suficiente para suplantar governos autoritários. O crescimento de ONGs e redes cívicas com ações transnacionais, muitas delas sustentadas por especialistas e centros de pesquisa universitários, e com amplos aportes financeiros oriundos de fundações e de governos, 148 renovou as atenções sobre o alcance e a eficácia política dos atores da sociedade civil.

Neste artigo, investigo as diferentes premissas que sustentam as formulações teóricas sobre o papel da sociedade civil para manter a democracia. Meu interesse não é oferecer uma abordagem dos tipos de propósitos normativos atribuídos às associações civis, nem examinar os elementos civis que promovem a democracia liberal, tampouco catalogar os efeitos democráticos das associações. Diversos autores já assumiram essa tarefa (Cohen e Arato, 1992a; Rosenblum, 1998; Ehrenberg, 1999; Warren, 2001; Seligman, 2002). Minha intenção é clarear os diferentes problemas relacionados às expectativas mais otimistas sobre o papel da sociedade civil no desenvolvimento de práticas democráticas. Argumento que a inclusão de uma série de problemas na agenda de pesquisa sobre a sociedade civil produz um quadro nuançado para que se aprecie o alcance de suas contribuições e limitações para aperfeiçoar a democracia. 
Este artigo está dividido em duas partes. Na primeira, exploro alguns dos principais problemas sobre o conceito de sociedade civil e indico as dificuldades existentes para delimitar as fronteiras desta esfera no mundo contemporâneo. O conceito de sociedade civil é amorfo e carrega consigo diversos sentidos, com diferentes conotações políticas. Na segunda, exploro alguns problemas que desafiam as expectativas correntes mais otimistas sobre a função da sociedade civil para fortalecer práticas democráticas, a saber: a) equívocos em fazer apologia dos atores da sociedade civil como veículos para a promoção da cidadania democrática; b) o risco de advogar o antiestatismo em nome do localismo e da comunidade; c) as tensões entre a afirmação de interesses individuais e coletivos, presentes na ação coletiva; d) a necessidade de diferentes formas de institucionalização para que a participação política se torne mais ampla e eficaz. A partir deste quadro mais geral, reconsidero o alcance das contribuições e das limitações da sociedade civil para o fortalecimento da democracia.

\section{Sociedade civil: complexa demarcação de fronteiras}

A demarcação do território da "esfera civil" ou da "sociedade civil" ${ }^{6}$ tornou-se uma questão cada vez mais disputada entre teóricos e comentadores. A própria herança do conceito de sociedade civil - independentemente de tomarmos como ponto de partida Hegel ou Tocqueville - legou um

\footnotetext{
${ }^{6}$ Os termos "sociedade civil" e "esfera civil" são complexos e empregados, muitas vezes, de forma intercambiável. Neste artigo, utilizo o termo "sociedade civil", de modo mais restrito, para designar algum tipo de vida associativa, englobando diversas relações cooperativas e formas distintas de organização. Já o termo "esfera civil" é utilizado de modo mais abrangente para designar o domínio dos cidadãos, definidos através de seu status como membros de uma comunidade política, o qual é assegurado pela regra da lei, pela igualdade jurídica, por direitos, deveres e liberdades cívicas. As relações na esfera civil se distinguem daquelas relações nas esferas não civis, como a vida familiar no reino privado e a vida econômica no mercado. Para distinções conceituais clássicas e contemporâneas desses termos, ver Ehrenberg (1999), Seligman (2002) e Alexander (2006).
} 
conjunto de dificuldades para a definição de suas fronteiras (Ehrenberg, 1999; Eberly, 2000; Seligman, 2002; Alexander, 2006). De modo geral, sociedade civil, na perspectiva contemporânea, refere-se ao conjunto de associações, grupos formais e informais e redes na sociedade, que existem fora da família (e das relações íntimas) e do Estado (e de instituições a ele ligadas, como o exército, os partidos políticos, os parlamentos e as instituições administrativas burocráticas). Sob essa perspectiva, a sociedade civil abrange o domínio das associações voluntárias, os movimentos sociais e outras formas de comunicação pública, como os media.

A exclusão da vida privada, doméstica ou familiar é particularmente contestada por autores filiados a correntes feministas, sob a alegação de que esta perspectiva estabelece fronteiras rígidas entre os domínios público e privado e torna-se cega para a experiência cotidiana de pessoas submetidas a diferentes formas de injustiça e a relações de poder 150 (Phillips, 2002; Young, 2002). Esta crítica parece ser fruto de uma confusão sobre os limites entre os domínios público e privado. Um ponto é dizer que as relações íntimas entre os membros da família e entre amigos são relações privadas e existem à parte da ação coletiva (Alexander, 2006, pp. 29-30; Mosher, 2002, pp. 218-220). Outro é afirmar que os focos potenciais de solidariedade ou contestação não podem penetrar as relações sociais de qualquer tipo, como as feministas parecem assumir. Ora, muitos movimentos sociais buscam desestabilizar consensos existentes na cultura majoritária que podem ser opressivos nas relações íntimas, sociais ou, ainda, legais, e politizá-los como questões de interesse comum, no reino público. Injustiças nas relações privadas podem assim se constituir como a base social de conflitos que se transportam para o nível político-institucional.

As fronteiras adjacentes ao domínio da economia são também alvo de controvérsia. Alguns autores contemporâneos - particularmente de origem liberal - incluem alguns 
setores econômicos como parte da sociedade civil, na medida em que eles envolvem algum tipo de vida associativa. Contudo, excluem organizações com interesses nitidamente econômicos, como a Nike, a IBM ou a Microsoft (Post e Rosenblum, 2002; Lomasky, 2002). Não obstante, a maioria dos autores, de diferentes afiliações teóricas (Touraine, 1988; Cohen e Arato, 1992a; Keane, 1998; Young, 2002; Alexander, 2006) separam a sociedade civil também da economia, por assumir que as organizações civis são aquelas que não têm como preocupação primária a acumulação de riqueza material ou as trocas no mercado. Apesar de considerarem importante a noção do indivíduo moral e economicamente autônomo - premissa liberal que serviu de base para a ideia da sociedade civil $^{7}$-, esses autores concebem atualmente a sociedade civil como uma comunidade ética, constituída através de um conjunto de princípios e vínculos morais. Nos moldes hegelianos, esses valores éticos são considerados pré-condição para o entendimento da sociedade civil como uma comunidade autorreguladora que existe entre o indivíduo e o Estado. Diferentemente do Estado, que organiza as ações através de regras e leis garantidas por meio da autoridade e do poder coercitivo, ou distintamente do mercado, que organiza as ações através de regulamentações regidas por imperativos impessoais da economia, a

\footnotetext{
${ }^{7}$ Muitos elementos do pensamento liberal clássico foram fundamentais para a constituição da noção de sociedade civil. Ao postular que a sociedade não deveria mais ser concebida em termos de uma ordem holista e hierárquica, mas, sim, constituída por indivíduos particulares, Locke e pensadores do iluminismo escocês tentam fundar a existência da ordem social na autonomia do indivíduo e em uma propensão inerentemente humana à reciprocidade inata, sem fazer recurso a nenhum referente externo ou transcendente. O princípio do autointeresse - que libertou os indivíduos para que pudessem perseguir a vida econômica e o lucro carrega consigo a ideia de desenvolvimento interpessoal numa arena de troca, fundada em valores derivados da reciprocidade e do reconhecimento individual. Muito além de qualquer utilitarismo, essas concepções serviram de base para a noção da sociedade civil como um reino da troca e da interação numa arena ética. Para exploração das origens da sociedade civil e sua transição para a modernidade, ver Seligman (2002) e Ehrenberg (1999).
} 
sociedade civil pressupõe distintas formas de solidariedade. A vida civil é baseada no ideal de autogoverno coletivo, o qual evoca a produção da decisão com possibilidade de entendimento recíproco numa arena ética ${ }^{8}$.

O ponto que me interessa destacar é que há, atualmente, uma crescente dificuldade em fixar fronteiras rígidas entre o Estado, o mercado e a esfera civil. Muitas iniciativas de atores cívicos contam com a parceria de agentes do governo local ou nacional ou, ainda, com agências do mercado, o que constitui um terreno híbrido de partilha de poder e de atuação (Baiocchi, 2005, 2006; Houtzager, Gurza Lavalle e Acharya, 2004; Wampler e Avritzer, 2004). Alguns setores de negócios - como cooperativas, uniões de crédito, empreendimentos comunitários e parcerias público-privadas com participação de ONGs - têm um desenho institucional híbrido e metas destinadas a gerar o bem coletivo ou fazer avançar interesses gerais (Chambers e Kopstein, 2001, 2008; Edwards, 152 2004; Alexander, 2006). Novas rotas para a participação política, em que atores cívicos estabelecem parcerias com agentes do governo e, mesmo, do mercado, estão se expandindo, enquanto outras formas mais tradicionais de participação encontram-se em declínio (Snow, Soule e Kriesi, 2005).

Quanto à demarcação de fronteiras, há, também, uma confusão corrente entre noções jurídicas, derivadas do liberalismo constitucional, e sociológicas, para definir a sociedade civil como um domínio "à parte" do Estado e do mercado. Alguns autores, atendo-se a uma definição sociológica, falam de sociedade civil como um domínio distinto do Estado,

\footnotetext{
${ }^{8}$ Cohen e Arato (1992a, p. 429), por exemplo, baseados na noção habermasiana de ação comunicativa, afirmam que a sociedade civil inclui "todas as instituições e formas associativas que requerem interação comunicativa para sua própria reprodução e que se baseiam primariamente em processos de integração social para a coordenação da ação dentro de suas fronteiras". De modo semelhante, Warren (2001, p. 8) afirma: "Não há um 'nós' em um mercado e, portanto, não há possibilidade estrutural do autogoverno coletivo, mas apenas um agregado de preferências individuais e firmas respondendo a essas preferências".
} 
mesmo em sociedades não democráticas. Tratam de sociedade civil, por exemplo, na China ou em sociedades islâmicas, uma vez que os indivíduos se agregam em associações voluntárias, de modo espontâneo, a partir da pluralidade dos próprios interesses, de maneira autônoma em relação ao Estado, sendo que esses grupos desempenham, ainda, muitas atividades que não são exercidas pelo Estado (Huang, 1993; Hanafi, 2002). Contudo, nesses casos, a sociedade civil não pode ser vista como uma esfera protegida de liberdade, uma vez que os indivíduos associados não se encontram vinculados por regra da lei ao Estado através de um sistema de direitos e de garantias constitucionais que limitem interferências não justificadas na esfera civil. Os indivíduos não gozam de direitos de liberdade e de expressão, de agregação e contestação, necessários para questionar e opor-se com eficácia ao Estado. Vale destacar, contudo, o valor dessas associações voluntárias para desafiar regimes autoritários ou para pressionar as instituições a se democratizarem.

Por fim, o debate sobre a globalização - o poder dos mercados globais e das comunicações; os regimes de comércio transnacionais e as novas formas políticas, como a União Europeia; a crescente complexidade de questões de escopo global, como os problemas ambientais; a proliferação de redes cívicas e ONGs que transcendem os domínios do Estado-nação - coloca novas questões sobre o entendimento das fronteiras do Estado e da sociedade civil. Teóricos mais entusiastas sustentam que uma "sociedade civil global" vem configurando uma nova forma de governança transnacional (Kaldor, 2003) ${ }^{9}$. Cabe reconhecer que os atores civis,

\footnotetext{
${ }^{9}$ Nas palavras de Kaldor (2003, p. 590), “um sistema de governança global emergiu [...] [pois] não se trata de um Estado singular, mas de um sistema em que os Estados se tornam crescentemente confinados por um conjunto de acordos, tratados e regras de caráter transnacional. De modo cada vez mais frequente, essas regras são baseadas, não apenas no acordo entre Estados, mas, [...] [sobretudo] no suporte público gerado pela sociedade civil global”.
} 
ao exercerem uma política transnacional, sem territorialidade definida, desempenham um papel fundamental para sustentar - questionar, criticar e fazer circular - certos discursos na esfera pública transnacional, estabelecendo interlocuções com organizações intergovernamentais (como a Unesco, o Conselho de Direitos Humanos, a Otan, o FMI). Contribuem, assim, para modificar a constelação de discursos sobre leis internacionais e cosmopolitas (Dryzek, 2006; Chambers e Kopstein, 2008; Warren, 2008).

As formas de atuação de redes cívicas transnacionais podem provocar alterações em decisões, cujas consequências alcançam corporações, estados e organizações intergovernamentais. Não obstante, elas não tornam os conceitos de sociedade civil e de Estado obsoletos, já que essas ações se imbricam, em grande parte, com a "sociedade civil doméstica” e as respectivas relações com os representantes políticos, como discutirei mais adiante. Como Chambers e Kopstein 154 (2008, p. 378) lembram, a vasta maioria das organizações, associações e dos movimentos sociais transnacionais possuem sedes em países que oferecem proteção às suas ações, dentro da ordem legal liberal estabelecida.

\section{A "boa" e "má" sociedade civil}

A definição de sociedade civil de origem liberal entende os cidadãos como membros de uma comunidade, unidos na busca por certos valores compartilhados e por certos fins (outros, além dos econômicos), que os leva a apoiar a associação da comunidade política que em parte os une. Essas características conduziram muitos pensadores, tanto de linhagem neoliberal quanto comunitarista, a entender os atores da esfera civil como aqueles capazes de sustentar valores democráticos fundamentais, tais como o voluntarismo, a autodeterminação, a inclusão altruísta e a liberdade. A celebração desses valores é exemplarmente formulada por Keane (1998, p. 6): 
A sociedade civil é uma categoria ideal-tipo [...] que tanto descreve quanto almeja uma complexa e dinâmica agregação de instituições não governamentais que tendem a ser não violentas, auto-organizatórias, autorreflexivas e permanentemente em tensão umas com as outras e com as instituições do Estado que enquadram, constroem e tornam essas atividades possíveis.

A famosa definição de sociedade civil de Walzer destaca o valor das afiliações voluntárias, baseadas no consenso, ao invés de adesões requeridas legalmente. A sociedade civil é o "espaço da associação humana não coercitiva e também o conjunto de redes relacionais - formadas em prol da família, da fé, do interesse e da ideologia” (Walzer, 1998, p. 124). $\mathrm{O}$ voluntarismo é particularmente valorizado por permitir que os indivíduos alcancem seus objetivos através do diálogo, da barganha ou da persuasão, ao invés de compromissos impostos por governos ou de incentivos mercadológicos proporcionados por firmas.

Em adição, muitos autores filiados à tradição tocquevilleana celebram as associações voluntárias porque elas ajudam a desenvolver nos indivíduos hábitos cívicos benéficos à democracia: habilidades participativas, confiança recíproca e tolerância mútua. Entre esses autores, muitos se mostram satisfeitos com a existência, mesma, das associações, desde que os indivíduos se unam por meio de regras cívicas, ou desde que o debate seja civilizado, independentemente da motivação para a agregação ou do conteúdo daquilo que é discutido. Para Putnam, por exemplo, as ligas de boliche são mais favoráveis à democracia que a prática de jogar boliche somente com parceiros individuais, porque as associações voluntárias ensinam os indivíduos a desenvolver valores e recursos necessários à democracia: autodisciplina, respeito mútuo, colaboração etc. Na visão de Putnam (2000, p. 357), as associações alimentam o capital social e o capital social 
alimenta o sucesso da democracia. Ainda que este autor reconheça que "as conexões comunitárias às vezes podem ser opressivas" e que o capital social, ao invés de proporcionar laços vinculantes (bridging social capital) pode levar ao separatismo (bonding social capital), ele não chega a desenvolver essa premissa de modo satisfatório, de modo a sistematizar os efeitos não liberais potencialmente presentes na vida associativa.

É preciso deixar claro que a coerção, a exclusão, a violência ou a desigualdade podem constituir qualquer sociedade civil tanto quanto aqueles valores sustentados como favoráveis à democracia. As associações voluntárias se distinguem fundamentalmente entre si porque elas incorporam valores e desenvolvem práticas que ajudam a promover a democracia ou que a obstruem. A República de Weimar - possuindo uma sociedade civil bem-organizada - deu origem e sustentou o nazismo. Na Itália do 156 pré-guerra e em países do leste europeu, grupos com altos níveis de participação se organizaram em torno da ideologia fascista. Em países da América Latina, no período ditatorial dos anos 1970, grupos geradores de capital social foram fundamentais para minar o exercício igualitário de direitos e as instituições democráticas (Armony, 2004). Em países subsaarianos, com altos níveis de vida associativa, diversos grupos promoveram genocídios (Edwards, 2004, p. 44).

Uma sociedade civil robusta pode servir a qualquer tipo de propósito, incluindo a perseguição e a admoestação a outros indivíduos e grupos, a incitação ao ódio ou à violência, ou, ainda, a sustentação de uma atmosfera geral de desconfiança e discórdia, como demonstram grupos como o $\mathrm{Ku}$ Klux Klan e outros, homofóbicos, xenófobos, separatistas, fundamentalistas, neonazistas etc. Mesmo associações com "boas intenções" podem produzir efeitos antidemocráticos em determinados contextos. É pois necessário tratar a agên- 
cia ética da "má sociedade civil"10 (Chambers e Kopstein, 2001) e incorporar as tendências nefastas, antiliberais e antidemocráticas das associações à teorização sobre tal esfera.

Assim, não se pode conceber a sociedade civil de modo abstrato, como uma "esfera autônoma de atividade democrática”. O simples entendimento da sociedade civil como uma esfera de atividade associativa voluntária, à parte do Estado e do mercado, não é suficiente para produzir distinções qualitativas importantes. O domínio da sociedade civil é altamente heterogêneo (Warren, 2001; Edwards, 2004). Algumas associações se mostram preocupadas com ações destinadas à convivência, à autoajuda ou simplesmente ao divertimento, ao passo que outras encampam uma agenda política, estabelecendo ações destinadas ao desenvolvimento ou à assistência aos cidadãos, à sustentação da esfera pública, ou, ainda, a exercer influência e pressão sobre órgãos do Estado e sobre agentes do mercado, bem como a estabelecer parcerias para gestão compartilhada. Essas ações podem ter alcance local, nacional ou transnacional. Enquanto alguns atores da esfera civil desenvolvem ideias progressistas, humanistas e democráticas, outros abraçam ideias ultraconservadoras, fundamentalistas e antidemocráticas. O que a sociedade civil realmente "é" somente pode ser apreendido através do exame cuidadoso das motivações e dos propósitos das associações; do escopo de suas metas e da natureza de suas ações em relação a certos desígnios da democracia; de sua organização interna; dos valores substantivos que promovem e do sistema de relações que estabelecem com outros atores na sociedade, em contextos sócio-históricos específicos; de seus efeitos e sua eficácia política em diferentes planos democráticos.

\footnotetext{
${ }^{10}$ Existe obviamente uma vastíssima literatura que investiga grupos ultraconservadores, fundamentalistas e totalitários. Contudo, esses estudos não se desdobraram sistematicamente em uma teorização pelas diferentes escolas que tratam da sociedade civil.
} 


\section{0 risco de advogar 0 antiestatismo em nome do localismo e da comunidade}

$\mathrm{O}$ avolumar-se da crítica às estruturas burocráticas do Estado como impermeáveis à vontade dos cidadãos levou muitos teóricos a celebrar o localismo e a fragmentação. As premissas derivadas dos escritos de Tocqueville e também de Rousseau - de que as pequenas unidades são estruturadas de modo mais democrático que as grandes unidades produzem a expectativa de que uma sociedade repleta de associações e corpos autorreguladores será provavelmente mais aberta e permeável à ação dos indivíduos. Alguns autores dos modelos de democracia participativa (Barber, 1984; Pateman, 1970; Berger e Neuhaus, 2000) e deliberacionista (Cooke e Kothari, 2001; Goodwin, 1998) também fazem avançar essa visão, ao sustentar que as associações locais requerem alto nível de participação e debate entre as pessoas, sendo que os próprios interesses (vistos como

158 fonte autêntica de reivindicações válidas) geram motivos consistentes para o estabelecimento da cooperação, do compromisso e do acordo. Algumas premissas em operação, aqui, são as de que os indivíduos sabem especificar e expressar melhor suas próprias necessidades que os representantes políticos ou os agentes que ocupam cargos públicos; as pessoas se mostram mais propensas a participar em questões políticas quando sabem que suas opiniões e preferências serão levadas em consideração ou que suas ações poderão ter consequências diretas e, portanto, participar faz diferença; as pessoas, no âmbito local, têm que viver com as consequências de suas ações e, logo, elas têm boas razões para exercer o poder de forma responsável.

Ao trabalhar sobre essas premissas, muitos autores se basearam no paroquialismo, no localismo e na hostilidade ao governo central. Daniel Bell, por exemplo, concede ênfase à atuação de organizações voluntárias, igrejas e comunidades e defende que as decisões devem ser tomadas 
localmente, sem o controle do Estado e suas burocracias. Nas palavras do autor, "A demanda por um retorno à sociedade civil é a demanda por uma escala manuseável da vida social" (Bell, 2000, p. 388). Bell prevê, assim, que a política local, de pequeno porte, proporciona práticas significativas como algo criado e moldado por compreensões sociais, em contraste com a aparelhagem política institucional abstrata e burocrática.

Por certo, um maior grau de solidariedade e cooperação entre os grupos e um maior engajamento com a política no domínio da vida cotidiana ou a participação no governo local são fatores importantes para o desenvolvimento de práticas democráticas. Contudo, a participação local e as associações, pelo simples fato de serem locais, não oferecem garantias contra o abuso, a burocracia ou a impermeabilidade às reformas. $\mathrm{O}$ neotocquevilleanismo ${ }^{11}$, ao conceder ênfase às associações voluntárias e às normas cívicas informais, produz noções muito restritas para proporcionar uma orientação geral e suficientemente abrangente para a compreensão do ambiente político atual, da sociedade altamente complexa, mercantilizada, pluralista, com altos níveis de desigualdade social. Ressaltar a importância das associações voluntárias não pode obscurecer a fundamental importância do sistema político mais amplo e das instituições políticas da sociedade.

Em primeiro lugar, as atividades vividas no dia a dia não são escolhidas livremente; ao invés disso, resultam de sistemas funcionais organizados e moldados por forças políticas e econômicas de amplo escopo. Ademais, as determinações e os constrangimentos oriundos da esfera política e econô-

${ }^{11}$ É preciso deixar claro que existem distintas tradições do tocquevilleanismo, de linhagens comunitarista e liberal, com orientações mais igualitárias ou conservadoras. Assim, os autores destacam funções distintas da sociedade civil, diante de um papel mais positivo e forte do Estado ou diante de um Estado mínimo. Ver Ehrenberg (1999), Seligman (2002), Chambers (2002), Chambers e Kopstein (2008). 
mica são também essenciais para se entender o que a sociedade civil "é" (Ehrenberg, 1999; Seligman, 2002). Como já apontado, não há nada inerente às associações cívicas que leve à pluralidade, à igualdade ou à participação política. As condições para a participação democrática são providas, em grande medida, por agentes e condições existentes fora da sociedade civil. O liberalismo constitucional sempre evidenciou que os Estados precisam estruturar o terreno das diversas formas associativas. As características do sistema legal, as garantias providas pelas regras da lei, os procedimentos administrativos, os sistemas de impostos têm efeitos palpáveis nos hábitos, nas normas e nas formas de organização ou na definição de afiliações das associações voluntárias, dos grupos de interesse e dos movimentos sociais. A configuração do mercado e a regulação da competição de interesses interferem na configuração dos laços de solidariedade e de confiança, necessários à manutenção da sociedade civil.

160 Em segundo lugar, a teorização antiestatista torna impossível apreender o potencial emancipatório da ação política. Muitas das demandas e reivindicações dos atores da esfera civil têm como alvo o sistema político e requerem atenção e resposta dos agentes do Estado para assegurar ou implementar direitos, para aliviar injustiças sociais ou para prover redistribuições de oportunidades e bens. Assim sendo, é preciso compatibilizar o domínio da vida cotidiana com grandes questões de democracia política e justiça social. Princípios abstratos e amplos ideais políticos não estão ancorados na experiência pessoal, local e imediata dos indivíduos, mas em tradições democráticas constituídas através de um amplo processo sócio-histórico, como uma experiência compartilhada e dinâmica. A despeito da lógica relativamente autônoma das esferas do Estado, da economia e da sociedade civil, o desafio das democracias atuais pressupõe desenhos institucionais e a configuração de práticas que possam se estender sobre essas esferas, perpassando-as. 
Diversos teóricos dos modelos de democracia participativa ou deliberacionista também apostam na descentralização e na participação local como forma de tornar os indivíduos mais potentes e de fortalecer a democracia (Fung e Wright, 2003; Fung, 2004, 2007; Baiocchi, 2005; Gastil e Levine, 2005). Algumas notas de cautela são necessárias aqui, já que não se pode supor que as associações cívicas - pelo simples fato de se auto-organizarem, por estarem enraizadas nos contextos práticos da vida cotidiana ou, ainda, por conquistarem autonomia política em alguma medida - se apresentem como força democratizante e racionalizadora da sociedade. A descentralização e a participação no nível local podem tanto limitar a arbitrariedade e promover o livre e justo acesso à produção da decisão política quanto podem, também, aniquilar o autogoverno. Novamente, tudo depende dos fatores em jogo, das relações que os sujeitos estabelecem entre si e do ambiente circundante. Muitos grupos locais, constituídos de maneira homogênea, são excludentes e refletem a distribuição da estrutura local de poder. Elites locais podem igualmente se valer de associações para fortalecer suas posições e perseguir interesses particulares, ao invés de interesses gerais. Sob tais condições, a descentralização significa, muitas vezes, o fortalecimento das desigualdades existentes. Alguns estudos sobre Town Meetings e fóruns destinados a promover escolhas de políticas públicas pelos cidadãos, organizados em torno das estruturas face a face que tanto impressionaram Tocqueville, demonstram que muitos "acordos" são arranjados antecipadamente - através da barganha, da chantagem ou da fraude (Dagnino, 2002; Baiocchi, 2005; Gutmann, 2007). Em circunstâncias em que as deliberações locais são contaminadas por fontes externas de influência, elas não ajudam a proteger os interesses dos indivíduos de maneira equânime e nem facilitam a distribuição de poder em situações em que os interesses se chocam. Pelo contrário, processos 
de produção de decisão coletiva através do debate, nessas situações, favorecem os grupos mais influentes na definição da agenda política e com maiores recursos retóricos na condução do debate, a expensas de grupos menos poderosos.

\section{Tensões entre os indivíduos e as coletividades para processar questões de interesse comum}

O elogio às associações baseadas na auto-organização voluntária e autorreflexiva como veículos capazes de desenvolver virtudes cívicas e promover engajamento faz supor, ainda, que somente o associativismo - e não a participação individualizada - sustenta o bom funcionamento da democracia. Na visão de Tocqueville, as associações voluntárias, além de serem um reservatório de cuidado, de autoajuda, de vida cultural e de inovação intelectual e política, constituíam uma proteção ao cidadão comum contra o governo, contra os interesses privados e, ainda, contra as maiorias. Nos 162 termos de Putnam, onde não há "engajamento cívico" (no plano local) a comunidade ficaria desprotegida diante de outros interesses. Apesar da importância das associações para tornar os indivíduos mais potentes para influenciar os negócios públicos e ganhar voz política -, não se pode negligenciar a importância e a eficácia de diversas formas de participação individualizada (Galston, 2000; Gomes, 2008). A democracia demanda, também, a "liberdade subjetiva" e a participação dos cidadãos como indivíduos (e não apenas como coletivos), uma vez que estes se encontram situados em diferentes posições e circunstâncias ou têm diferentes ideias (Habermas, 1997; Cohen, 1997, pp. 80-81; Fraser, 2003, p. 31). Por um lado, isso significa que os indivíduos e grupos negociam entre si o que conta como boa vida e planejam o próprio modo de persegui-la, dentro dos limites que asseguram igual liberdade para os outros. Por outro lado, isso significa que a mesma autonomia privada (ou individual) se torna uma forma de proteção contra 
tradições, regras ou lealdades de grupos mais reconhecidas como válidas $^{12}$. Além disso, deve-se reconhecer que há sujeitos não associados e que, no entanto, mantêm alto nível de informação sobre os negócios da política e participam das mais diversas práticas democráticas sem, contudo, estarem afiliados a alguma associação. Há, hoje, uma série de manifestações e protestos eficazes, do ponto de vista político, sem que necessariamente os indivíduos sustentem um nível de engajamento duradouro e intenso com as associações voluntárias (Snow, Soule e Kriesi, 2005).

É certo que a questão que se coloca não é a de que devemos escolher entre os indivíduos ou as associações, e, mais especificamente, as associações cívicas, para sustentar o bom funcionamento da democracia; uma democracia saudável requer ambos. Contudo, esta resposta não dá conta do verdadeiro problema, a saber: a tensão sempre presente entre o elemento consensual e cívico, correspondente à inserção numa dada comunidade, e o elemento frequentemente conflituoso correspondente à afirmação autônoma de cada membro individual da coletividade. Esta questão remete à tradicional indagação da teoria política: o livre desenvolvimento de cada um é compatível com o livre desenvolvimento de todos (Held, 1987)? Esse ponto recupera polêmicas acerca do modo pelo qual interesses individuais podem ser perseguidos na arena social e como o bem público pode ser buscado via esfera privada (Rawls, 1971, 2001; Habermas, 1997). Não pretendo, aqui, desenvolver as inúmeras controvérsias sobre a maneira apropriada de processar reivindicações conflitantes e estabelecer regras normativas vinculantes na sociedade,

\footnotetext{
${ }^{12}$ Adaptando esses princípios liberais para os dilemas do multiculturalismo, Benhabib (2002, p. 131) enfatiza que "reciprocidade igualitária", "autonomeação voluntária" de um indivíduo a qualquer grupo (cultural, religioso ou linguístico) e "liberdade de associação e de dissociação" precisam ser valorizados a fim de evitar o aprisionamento dos indivíduos em suas comunidades, quando se busca a inclusão de minorias excluídas.
} 
diante dos conflitos de interesse e desentendimentos morais constantes entre indivíduos ou grupos.

Alguns desdobramentos deste amplo debate, que interessam mais diretamente ao desenvolvimento de meu argumento, dizem respeito à certa ambivalência existente entre a dimensão cívica e a dimensão civil da cidadania, na medida em que os valores encarnados por cada uma delas tendem a negar os da outra (Galston, 2000; Reis, 2000). A ideia de cívico traz consigo a noção de deveres e responsabilidades do cidadão, à sua propensão ao comportamento solidário e à observância das virtudes cívicas derivadas de sua identificação com a coletividade. Por exemplo, aos neotocquevilleanos interessa mostrar que os cuidados com a comunidade (civitas) ou, nos termos de Putnam, o "engajamento cívico", acontecem porque a própria identidade e os interesses dos indivíduos são marcados pela inserção nessa comunidade. Comunidade, ou aquilo que une os iguais, é sempre algo 164 particular. Talvez por isso mesmo, há um constante clamor (pelo menos no contexto dos EUA) por estabelecer o senso de pertencimento às comunidades, diante daquilo que é visto como individualismo, presente nas relações abstratas, formais e legalistas da sociedade contemporânea. Contudo, não se pode supor que o "cuidado" - demonstrado com os membros de uma determinada comunidade - se estenderá aos diferentes, estranhos e estrangeiros (Alexander, 2006, p. 34; Benhabib, 2002, pp. 164-165; Fraser, 2003, pp. 58-59; Gomes, 2008, p. 271). Como discutido acima, muitos grupos negam a tolerância e o respeito a outros indivíduos e grupos da sociedade e não vivem de acordo com os ideais da cidadania democrática.

Em contraste, a ideia de civil encontra-se associada com a busca moderna pela afirmação dos direitos dos membros individuais da coletividade, dizendo respeito ao tratamento de todos os indivíduos como agentes iguais na democracia política e com igual liberdade de viver suas próprias vidas 
como eles as compreendem, de modo consistente com a liberdade dos outros. Trata-se de reivindicações universalistas dos direitos do indivíduo, os quais se encontram na base do requerimento abstrato de igual tratamento, presente tanto nos momentos de afirmação de direitos civis quanto nos de direitos políticos e direitos sociais (Marshall, 1967). Incorporada à perspectiva liberal ortodoxa, a dimensão civil da cidadania significa que os indivíduos se afirmam por si mesmos, ou autonomamente - isto é, na esfera privada contra intervenções ilícitas na liberdade, na vida e na propriedade -, de uma maneira que não só prescinde do Estado, mas, também, que pode até opor-se eficazmente a ele. Para além da proteção contra as arbitrariedades do Estado, as perspectivas liberais atuais apelam para a dimensão universalista da cidadania - e noções correlatas do governo da lei, da igualdade formal, das liberdades civis - para contestar os particularismos e as hierarquias da sociedade e eliminar as disparidades não justificadas. Não se pode negar que as visões cívico-republicanas da cidadania e as demandas por "igualdade de status" são encontradas em muitos movimentos sociais contemporâneos, sejam eles ligados a conflitos relacionados à liberdade política, ao crescimento econômico, à integridade cultural ou a crenças e práticas religiosas (Benhabib, 2002, pp. 40-42; Fraser, 2003, pp. 54-60).

Para os propósitos de minha argumentação, é importante apontar que os interesses individuais e focos de solidariedade coletiva e os correspondentes dissensos não permitem estabilizar permanentemente o que conta como razoável e legítimo nas demandas dos agentes civis. Este é um conflito inarredável, já que não é possível constituir um senso de comunidade - definida como uma solidariedade compartilhada, baseada em vínculos concretos dados pela história, por ideias, amor, cuidado e amizade - entre os atores sociais, concebidos em termos de indivíduos autônomos, na sociedade complexa, de larga escala, constituída por siste- 
mas valorativos plurais. Este dilema, já presente em meados do século XVIII, foi exemplarmente tematizado por Weber. Na modernidade, quanto mais as relações entre os indivíduos são definidas por critérios abstratos - regras formais do Estado, normas legais ou imperativos do mercado -, menos o reino público pode ser definido através de uma solidariedade compartilhada; menos as motivações para a reciprocidade e a confiança podem ser realizadas no reino público. Nas sociedades contemporâneas, como resultados das migrações de massa, das diásporas, da cultura de massa globalizada e da esfera pública transnacional, a ordem cultural é eticamente pluralista e os padrões de valor e horizontes de avaliação são intensamente contestados (Benhabib, 2002; Fraser, 2003).

Neste cenário, não há como promover distinções objetivas entre demandas e reivindicações de grupos diversos da esfera civil. Essa é uma dificuldade que persiste na vida política, mesmo quando ela é constituída por indivíduos 166 e grupos com orientação democrática, para além daqueles grupos extremistas e notadamente antidemocráticos. Como Walzer reconhece,

a vida associativa da sociedade civil é o terreno em que todas as visões de boa vida são colocadas em prática e testadas, e se provaram imparciais, incompletas e, em última instância, insatisfatórias [...]. Não há possibilidade de escolher, como os velhos anarquistas, apenas a sociedade civil (Walzer, 1998, p. 132).

As demandas de caráter coletivo sempre afetam, na sociedade, os demais indivíduos e coletivos. Os grupos reivindicantes frequentemente fazem um apelo também para que seus concidadãos aceitem certos objetivos ou que reconheçam determinadas orientações valorativas, sejam elas para igual tratamento legal; para proteção à integridade cultural; para combater desvantagens vivenciadas por cer- 
tas coletividades ou, ainda, para a redistribuição de oportunidades e recursos necessários ao bem-estar de um determinado grupo. Assim, o conflito de interesses e o dissenso moral na política democrática são constantes e inevitáveis.

Se não há como observar e julgar objetivamente as reivindicações e as ações empreendidas pelos atores cívicos, esse julgamento, não só do ponto de vista filosófico e político, mas também do ponto de vista prático, pressupõe a agência ética dos cidadãos e a participação dos concernidos em abrangentes debates na esfera pública (Habermas, 1997; Benhabib, 2002; Fraser, 2003). O estabelecimento de padrões críticos - tais como a igualdade cívica, a igual liberdade e o sistema de oportunidades - estão sempre sujeitos à interpretação para emprego em situações práticas e abertos à contestação. É essa articulação entre a esfera civil e o Estado, e as distintas formas de institucionalização da participação oriunda da sociedade civil, que discutirei brevemente na próxima seção.

\section{Participação civil e institucionalização}

Nas seções anteriores, minha argumentação apoiou-se no entendimento de que o Estado e a sociedade civil devem se tornar a condição para o desenvolvimento democrático um do outro (Held, 1987; Habermas, 1997). O Estado oferece as condições institucionais para o funcionamento dos agentes civis, sendo que o sistema de direitos regulamenta direitos, deveres e poderes dos cidadãos e estipula um conjunto de procedimentos para a contestação, a discussão razoável e a proposição de novas regras. No contexto democrático, a articulação de qualquer demanda de cidadãos ou grupos - envolvendo novos princípios, valores ou bens - é o exercício de um direito democrático de discutir e buscar implementar emendas nas regras existentes de uma dada comunidade política e, consequentemente, alterar as relações de governança em vigor. 
Assim, do ponto de vista normativo, não cabe esperar o progresso de solidariedades autônomas na sociedade civil, prescindindo do Estado e do mercado. Um dos maiores desafios da governança complexa é construir uma aparelhagem político-institucional capaz de institucionalizar a discussão e a participação de cidadãos e de assegurar variadas formas de controle e fiscalização. As articulações da esfera civil com o Estado democrático se dão em diferentes planos (Chambers e Kopstein, 2008; Warren, 2008). As formas para institucionalizar a participação civil são diversas e os desenhos institucionais não são necessariamente excludentes.

Há, surpreendentemente, no estágio atual do debate, amplas áreas de convergência nas proposições de autores filiados a diferentes tradições do pensamento político particularmente entre deliberacionistas e participacionistas. Sob a perspectiva da política discursiva ou deliberativa, as decisões públicas devem ser produzidas, ou pelo menos 168 influenciadas, pelos cidadãos, através do debate crítico e da tentativa de persuadir uns aos outros sobre os valores ou os cursos de ação que devem ser buscados conjuntamente (Habermas, 1997; Cohen, 1997; Bohman, 2000). Autores filiados à tradição da democracia participativa preocupam-se com novas formas de institucionalidade capazes de conferir um caráter formal às demandas oriundas dos atores civis (Fung, 2004, 2007; Fung e Wright, 2003; Houtzager, Gurza Lavalle e Acharya, 2004; Avritzer, 2007). Buscam pensar em formas de assegurar uma participação empoderada, concebida, sobretudo, como uma participação sustentada por incentivos institucionais e por proteções contra vulnerabilidades econômicas ou contra outros poderes coercitivos. Preocupam-se, assim, não só em expandir a esfera pública para que todos tenham voz - entendendo "voz" como um instrumento que torna os cidadãos mais potentes (empowered) - mas também em aperfeiçoar e imaginar desenhos institucionais, com especificações sobre quem exata- 
mente deve deliberar, onde, quando e como. Desenhos institucionais diversos - tais como os "planning cells", "citizens juries", "deliberative pools", "consensus conferences", "conselhos gestores", "orçamento participativo" - estabelecem vínculos variados entre representantes e representados, com novas formas de produzir definições políticas e modos de assegurar accountability (Avritzer, 2007; Baiocchi, 2005; Fung, 2004, 2007; Gurza Lavalle, Acharya e Houtzager, 2005; Gurza Lavalle, Houtzager e Castello, 2006). Entre as exigências atuais para uma governança complexa, pluralista, em sociedades pós-tradicionais, está o terreno diversificado de associações civis, com participação política em arenas diversas de comunicação e controle, com vários níveis de organização. No campo heterogêneo da sociedade civil, muitas associações se especializam em ações específicas e, por isso mesmo, não são aptas a exercer outras funções diante dos diversos propósitos da democracia.

A sociedade civil, em suas diferentes funções, é e continuará sendo agente crucial da vida política. O debate sobre a sociedade civil - abrangendo questões sobre quem ou o que está nela incluído; quais os vínculos se estabelecem entre seus membros; que benefícios e riscos as associações voluntárias oferecem aos seus membros e à sociedade em geral; como e por que a sociedade civil é importante - continua a suscitar inquietações entre teóricos e observadores e a mobilizar disputas que atravessam diferentes tradições do pensamento político e social.

Neste artigo, busquei explorar algumas das premissas principais que ancoram as expectativas otimistas sobre o papel das associações voluntárias e as organizações cívicas nas práticas democráticas. Frente aos principais deslocamentos postos hoje no debate sobre a sociedade civil, busquei 
evidenciar um conjunto de problemas que desafiam algumas perspectivas unilaterais. A compreensão de diversas ordens de problemas, discutidos ao longo deste artigo, não pode obnubilar a importância da esfera civil para o futuro da democracia. Devem persistir os desafios para construir instituições políticas com uma aparelhagem adequada e suficientemente flexível para ampliar a participação e a discussão criativa e transformadora e, também, para garantir que os processos de controle e prestação de contas funcionem democraticamente. Diante das profundas transformações no mundo contemporâneo globalizado e da enorme versatilidade dos agentes da esfera civil para construir modos alternativos, inéditos e até mesmo inesperados de atuação, o debate sobre a sociedade civil tem, certamente, vida longa.

\section{Rousiley C. M. Maia}

é professora associada no Departamento de Comunicação 170 Social da UFMG.

\section{Referências bibliográficas}

ALEXANDER, J. C. 2006. The civil sphere. New York: Oxford University Press. ARMONY, A. 2004. The dubious link: civic engagement and democratization. Stanford: Stanford University Press.

AVRITZER, L. 2002. Democracy and the public space in Latin America. Princeton: Princeton \& Oxford.

2007. "Sociedade civil, instituições participativas e representação: da autorização à legitimidade da ação”. Dados, vol. 50, no 3, pp. 443-476.

BAIOCCHI, G. 2005. Militants and citizens: the politics of participatory democracy in Porto Alegre. Stanford: Stanford University Press.

. 2006. "Civilizing force of social movements: corporate and liberal codes in Brazil's public sphere". Sociological Theory, vol. 24, no 4, pp. 285-311.

BARBER, B. R. 1984. Strong democracy: participatory democracy for a new age. Berkerley: University of California Press.

BELL, D. 2000. "American exceptionalism revisited: the role of civil society”. In: EBERLY, D. E. (org.). The essential civil society reader. Oxford: Rowman \& Littlefield Publishers. 
BELLAH, R. 2000. "The good society: we live through our institutions". In: EBERLY, D. E. (org.). The essential civil society reader. Oxford: Rowman \& Littlefield Publishers.

BENHABIB, S. 2002. The claims of culture: equality and diversity in the global era. Princeton: Princeton University Press.

BERGER, P. L.; NEUHAUS, R. J. 2000. "To empower people: from state to civil society”. In: EBERLY, D. E. (org.). The essential civil society reader. Oxford: Rowman \& Littlefield Publishers.

BOHMAN, J. 2000. Public deliberation: pluralism, complexity and democracy. Massachusetts: MIT Press.

CHAMBERS, S. 2002. "A critical theory of civil society". In: CHAMBERS, S.; KYMLICKA, W. (orgs.). Alternative conceptions of civil society. Princeton: Princeton University Press.

; KOPSTEIN, J. 2001. "Bad civil society". Political Theory, vol. 29, nº 6 , pp. $837-65$.

2008. "Civil society and the state". In: DRYZEK, J.; HONG, B.; PHILLIPS, A. (orgs.). The Oxford handbook of political theory. Oxford: Oxford University Press.

COHEN, J. 1997. "Deliberation and democratic legitimacy". In: BOHMAN, J.; REHG, W. (orgs.). Deliberative democracy. London: MIT Press.

; ARATO, A. 1992a. Civil society and political theory. Cambridge: MIT Press.

1992b. "Politics and the concept of civil society". In: HONNETH, A; McCARTHY, T; OFFE, C.; WELLMER, A. (orgs.). Cultural-political interventions in the unfinished project of enlightenment. Cambridge: Cambridge University Press.

COOKE, B.; KOTHARI, U. 2001. Participation: the new tyranny? London: Zed Books.

DAGNINO, E. 2002. "Sociedade civil e espaços públicos no Brasil". In: (org.). Sociedade civil e espaços públicos no Brasil. Rio de Janeiro: Paz e Terra.

DOIMO, A. M. 1995. A vez e a voz do popular. movimentos sociais e participação política no Brasil pós-70. Rio de Janeiro: Relume-Dumará.

DRYZEK, J. 2006. Deliberative global politics. Malden: Polity Press.

EBERLY, D. E. 2000. "The meaning, origins and applications of civil society". In: (org.). The essential civil society reader. Oxford: Rowman \& Littlefield Publishers.

EDWARDS, M. 2004. Civil society. Cambridge: Polity Press.

EHRENBERG, J. 1999. Civil society: the critical history of an idea. New York: New York University Press. 
FRASER, N. 2003. "Social justice in the age of identity politics: redistribution, recognition, and participation”. In: FRASER, N.; HONNETH, A. Redistribution or recognition: a political-philosophical exchange. London/ Nova York: Verso.

FUNG, A. 2004. Empowered participation: reinventing urban democracy. Oxford: Princeton University Press. 2007. "Minipublics: deliberative designs and their consequences". In: ROSENBERG, S. (org.). Can people govern? Deliberation, participation and democracy. New York: Palgrave.

; WRIGHT, E. O. 2003. "Thinking about empowered participatory governance”. In: Deepening democracy: institutional innovation and empowered participatory government. London: Verso.

GALSTON, W. A. 2000. "Individualism, liberalism and democratic civil society". In: EBERLY, D. E. (org.). The essential civil society reader. Oxford: Rowman \& Littlefield Publishers.

GASTIL, J.; LEVINE, P. 2005. The deliberative democracy handbook: strategies for effective civic engagement in the $21^{\text {st }}$ century. San Francisco: Jossey-Bass.

GOMES, W. 2008. "Capital social, democracia e televisão em Robert Putnam”. In: _ _ MAIA, R. C. M. (orgs.). Comunicação e democracia: problemas e perspectivas. São Paulo: Paulus.

GOODWIN, P. 1998. “'Hired hands' or 'local voice': understandings and experience of local participation on conservation". Transactions of the Institute of British Geographers, vol. 23, no 4, pp. 481-499.

GURZA LAVALLE, A.; ACHARYA, A.; HOUTZAGER, P. 2005. "Beyond comparative anecdotalism: lessons on civil society and participation from São Paulo”. Brazil World Development, vol. 6, pp. 951-964.

; HOUTZAGER, P. P.; CASTELLO, G. 2006. "Representação política e organizações civis: novas instâncias de mediação e os desafios da legitimidade”. Revista Brasileira de Ciências Sociais, vol. 21, no 60, pp. $43-66$.

GUTMANN, N. 2007. "Bringing the mountain to the public: dilemmas and contradictions in the procedures of public deliberation initiatives that aim to get 'ordinary citizens' to deliberate policy issues. Communication Theory, vol. 17, pp. 411-438.

HABERMAS, J. 1997. Direito e democracia. Rio de Janeiro: Tempo Brasileiro.

HANAFI, H. 2002. "Conceptions of civil society: a reflexive Islamic approach”. In: CHAMBERS, S.; KYMLICKA, W. (orgs.). Alternative conceptions of civil society. Princeton: Princeton University Press.

HELD, D. 1987. Modelos de democracia. Belo Horizonte: Paideia. 
HOUTZAGER, P. P.; GURZA LAVALLE, A.; ACHARYA, A. 2004. "Atores da sociedade civil e atores políticos: participação nas novas políticas democráticas”. In: AVRITZER, L. (org.). A participação em São Paulo. São Paulo: Ed. Unesp.

HUANG, P. 1993. "Public sphere/civil society in China". Modern China, vol. 19, nㅇ 2, pp. 216-240.

KALDOR, M. 2003. "The idea of global civil society". International Affairs, vol. 79, pp. 583-593.

KEANE, J. 1998. Civil society: old images, new visions. Stanford: Stanford University Press.

LOMASKY, L. E. 2002. "Classical liberalism and civil society". In: CHAMBERS, S.; KYMLICKA, W. Alternative conceptions of civil society. Princeton: Princeton University Press.

MARSHALL, T. H. 1967. Cidadania, classe social e status. Rio de Janeiro: Jorge Zahar.

MOSHER, M. A. 2002. "Are civil societies the transmission belts of ethical tradition?”. In: CHAMBERS, S.; KYMLICKA, W. (orgs.). Alternative conceptions of civil society. Princeton: Princeton University Press.

PATEMAN, C. 1970. Participation and democratic theory. Cambridge: Cambridge University Press.

PHILLIPS, A. 2002. "Does feminism need a conception of civil society?".

In: CHAMBERS, S.; KYMLICKA, W. (orgs.). Alternative conceptions of civil society. Princeton: Princeton University Press.

POST, R. C.; ROSENBLUM, N. L. 2002. "Introduction”. In: (orgs.). Civil society and government. Princeton: Princeton University Press.

PUTNAM, R. D. 2000. Bowling alone: the collapse and the revival of American community. New York: Simon \& Schuster.

RAWLS, J. 1971. A theory of justice. Cambridge: Harvard University Press. 2001. Justice as fairness. Cambridge: Belknap Press.

REIS, F. W. 2000. “Cidadania, mercado e sociedade civil”. In: Mercado $e$ utopia: teoria política e sociedade brasileira. São Paulo: Edusp.

SELIGMAN, A. B. 2002. "Civil society as idea and ideal". In: CHAMBERS, S.; KYMLICKA, W. (orgs.). Alternative conceptions of civil society. Princeton: Princeton University Press.

SNOW, D. A.; SOULE, S. A.; KRIESI, H. 2005. "Mapping the terrain". In: The Blackwell companion to social movements. Malden: Blackwell Publishers. TOCQUEVILLE, A. 1987. A democracia na América. Belo Horizonte: Itatiaia. TOURAINE, A. 1988. Return to the actor. Minneapolis: University of Minnesota Press. 
WALZER, M. 1998. "The idea of civil society: a path to social reconstruction”. In: DIONNE, E. J. (org.). Community works: the revival of civil society in America. Washington: Brookings Institution Press.

WAMPLER, B.; AVRITZER, L. 2004. "Públicos participativos: sociedade civil e novas instituições no Brasil democrático". In: COELHO, V. S. P.; NOBRE, M. (orgs.). Deliberação e participação: teoria democrática e experiências institucionais no Brasil contemporâneo. São Paulo: Ed. 34.

WARREN, M. E. 2001. Democracy and association. Princeton: Princeton University Press.

. 2008. "Democracy and the state". In: DRYZEK, J.; HONG, B.; PHILLIPS, A. (orgs.). The Oxford handbook of political theory. Oxford: Oxford University Press.

YOUNG, I. M. 2002. Inclusion and democracy. New York: Oxford University Press. 
rias deterministas da política que procuram predizer o comportamento político falham porque elas ignoram a autonomia relativa da política. É através da política, no quadro do Estado democrático, que homens e mulheres constroem seu Estado e sua sociedade.

Palavras-chave: Estado; Política; Desenvolvimento; Democratização.

\section{THE POLITICAL CONSTRUCTION OF THE STATE}

In the relations between society and the state, the two forms of politically organized societies - the nation and civil society - play a key role, as also do class coalitions and political pacts. The relation between both is dialectical, but, initially, the state exerts more influence on the society; as democratization takes place this relation gradually changes in favor of society. Despite the fact that politics (the art of governing the state) is subjected to economic and 256 political constraints, it counts with a relative autonomy. It is not the state but politics that has relative autonomy. Whereas society and the economy are the realm of necessity, politics is the realm of men's will and freedom. The deterministic political theories that search to predict political behavior fail because they ignore this relative autonomy of politics. It is through politics, in the framework of the democratic state, that men and women build their state and their society.

Keywords: State; Politics; Development; Democratization.

\section{O PAPEL DEMOCRÁTICO DA SOCIEDADE CIVIL EM QUESTÃO}

ROUSILEY C. M. MAIA

$\mathrm{O}$ artigo tem por objetivo examinar algumas das premissas otimistas que levaram pensadores políticos e sociais de diferentes tradições a ressaltar o papel democrático 
da sociedade civil. Partindo do debate contemporâneo sobre a sociedade civil, investigam-se os seguintes problemas: a visão das associações como agentes que promovem exclusivamente a cidadania democrática; a celebração do localismo e o poder de comunidades em detrimento do papel do Estado; as tensões inevitáveis entre a afirmação de interesses pessoais e a solidariedade coletiva; diversos níveis de articulação entre a participação civil e a institucionalização para fortalecer a democracia. Conclui-se que o declínio do entusiasmo não deve ser confundido com o declínio da importância da sociedade civil para o futuro da democracia.

Palavras-chave: Sociedade civil; Associativismo; Participação política; Democracia.

\section{CHALLENGING THE DEMOCRATIC ROLE OF CIVIL SOCIETY}

This paper critically assesses some assumptions that lead political and social thinkers of various traditions to emphasize the democratic role of the civil society. Starting with contemporary debates on civil society, the author investigates the concept of civil society and examines the following problems: the view of civic associations as exclusively democratic citizenship-promoting agents; the celebration of localism and the power of communities to the detriment of the role of the Estate; the unavoidable tensions between the affirmation of personal interests and collective solidarity; and several levels of articulations between civil participation and institutionalization required to revitalize democracy. This assessment leads to the conclusion that the decline of enthusiasm should not be mistaken for the decline of the importance of civil society for the future of democracy.

Keywords: Civil society; Associativism; Political participation; Democracy. 